\title{
Linx
}

Revue des linguistes de l'université Paris X Nanterre

$8 \mid 1996$

Du dire et du discours

\section{Bibliographie des travaux de Denise Maldidier (1970-1992)}

Jacques Guilhaumou

\section{(2) OpenEdition}

\section{Journals}

Édition électronique

URL : http://journals.openedition.org/linx/1185

DOI : 10.4000/linx.1185

ISSN : 2118-9692

\section{Éditeur}

Presses universitaires de Paris Nanterre

\section{Édition imprimée}

Date de publication : 1 septembre 1996

Pagination : 243-247

ISSN : 0246-8743

\section{Référence électronique}

Jacques Guilhaumou, « Bibliographie des travaux de Denise Maldidier (1970-1992)», Linx [En ligne],

8| 1996, mis en ligne le 18 juillet 2012, consulté le 01 mai 2019. URL : http://journals.openedition.org/ linx/1185; DOI : 10.4000/linx.1185

Ce document a été généré automatiquement le 1 mai 2019.

Département de Sciences du langage, Université Paris Ouest 


\title{
Bibliographie des travaux de Denise Maldidier (1970-1992)
}

\author{
Jacques Guilhaumou
}

\section{9}

1 « Vocabulaire politique de la guerre d'Algérie : analyse linguistique d'après six quotidiens parisiens (novembre-décembre 1954)», communication au Colloque de lexicologie politique de Saint-Cloud (26-28 avril 1968), Cahiers de lexicologie, 1969-II, p. 101 - 113, Didier-Larousse.

\section{0}

2 Analyse linguistique du vocabulaire politique de la guerre d'Algérie, thèse de troisième cycle, Paris-X-Nanterre, dactylographiée .

\section{1}

3 a. «Lecture des discours de De Gaulle par six quotidiens parisiens : 13 mai 1958», Langue française, 9, mars 1971, p. 34-46.

4 b. «Le discours politique de la guerre d'Algérie: approche synchronique et diachronique», Langages, 23, septembre 1971, p. 57-86.

5 c. «Discours politique et guerre d'Algérie », La Pensée, 157, juin 1971.

\section{2}

6 (En collaboration avec Claudine Normand et Régine Robin) «Discours et idéologie : quelques bases pour une recherche », Langue française, 15, septembre 1972, p. 116-141. 


\section{4}

7 (En collaboration avec Régine Robin) «Polémique idéologique et affrontement discursif en 1776 : les grands édits de Turgot et les remontrances du Parlement de Paris », Langage et idéologies. Le discours comme objet de l'histoire, Les Éditions ouvrières, p. 13-81.

\section{6}

8 (En collaboration avec Régine Robin) «Du spectacle au meurtre de l'événement: reportages, commentaires et éditoriaux de presse à propos de Charléty (mai 1968)", Annales ESC, mai-juin 1976.-Également publié, augmenté du corpus, dans Pratiques, 14, mars 1977.

\section{8}

9 a. (En collaboration avec Jacques Guilhaumou) Article « Langage » dans le dictionnaire de La Nouvelle Histoire sous la direction de Jacques Le Goff, CEPL, p. 304-308.

b. (En collaboration avec Jacques Guilhaumou) «La constitution du corpus», communication au colloque d'Urbino sur le discours politique, juillet 1978.

\section{9}

11 (En collaboration avec Jacques Guilhaumou) «Courte critique pour une longue histoire ou les (mal)leurres de l'analogie », Dialectiques 26, p. 7-23.

\section{0}

12 a. (En collaboration avec Jacques Guilhaumou) «L'affaire Fiszbin : analyse d'énoncés ", Politique aujourd'hui, $\mathrm{n}^{\circ}$ 3-4, p. 105-111.

13 b. (En collaboration avec Claudine Normand) «Faut-il se demander ce que parler veut dire? », LINX 3, Paris X - Nanterre.

\section{1}

14 a. (En collaboration avec Jacques Guilhaumou) «L'affaire Fiszbin: un exemple de résistance ", communication au colloque «Matérialités discursives» de Paris X Nanterre, avril 1980.

15 Paru dans Matérialités discursives, Presses Universitaires de Lille, p. 75-92.

16 b. (En collaboration avec Jacques Guilhaumou) «L'analyse du discours à la recherche de l'historicité, une tentative. Du propos au mot d'ordre: "Du pain" et (la question) des subsistances. La journée du 4 septembre 1793 », LINX, 4, p. 69-105. 
17 Également publié dans les Actes du $\mathrm{II}^{\mathrm{e}}$ colloque de lexicologie politique, Saint-Cloud, 15-20 septembre 1980, vol. 3, Klincksieck, p. 831-854.

\section{2}

18 (En collaboration avec Claudine Normand) « Passer d'un discours à l'autre : la contraction de texte », première partie, Langue française, 53 ; seconde partie, LINX, 7, p. 77-105.

\section{3}

(En collaboration avec Jacques Guilhaumou) Article «Discours (analyse de)», Grand dictionnaire encyclopédique, Larousse, tome III.

\section{4}

a. "Michel Pêcheux: une tension passionnée entre la langue et l'histoire ", Histoire et Linguistique, édition MSH, p. XI-XIV.

b. (En collaboration avec Jacques Guilhaumou) «Coordination et discours : Du pain et X à l'époque de la Révolution française », LINX, 10, p. 96- 117.

c. (En collaboration avec Jacques Guilhaumou) «Analyse discursive d'une journée révolutionnaire : 4 septembre 1793 », Le Discours social et ses usages, Cahiers de recherche sociologique de l'UQAM, vol. 2, 1, Montréal, p. 137-158.

d. (En collaboration avec B. Conein, F. Gadet, J. Guilhaumou, J.-M. Marandin et M. Pêcheux) «L'analyse de discours en France », Buscila, 1, p. 53-64.

e. (En collaboration avec Bernard Conein et Jacques Guilhaumou) «L'analyse de discours comme contexte épistémologique », Mots, 9, mars, p. 25-30. »

\section{5}

a. (En collaboration avec Claudine Normand) «Quelle sorte d'objet est le sujet de la langue ?", LINX, 13, p. 7-47.

b. (En collaboration avec Jacques Guilhaumou) «À propos de l'affaire Fiszbin : discours communiste et résistance de l'appareil », Le Discours politique, Recherches en analyse politique comparée (Université de Bordeaux-I), communication au colloque d'Aix-enProvence sur « Les Résistances », septembre 1980.

\section{6}

a. Composition du numéro 81 de Langages, mars, "Analyse de discours, nouveaux parcours ", hommage à Michel Pêcheux, rédaction de l'Avant-propos.

b. (En collaboration avec Jacques Guilhaumou) « Effets de l'archive, l'analyse de discours du côté de l'histoire ", Langages, 81, p. 43-56. 
c. (En collaboration avec Jacques Guilhaumou) « De l'énonciation à l'événement discursif en analyse de discours", communication au colloque sur l'Histoire des théories de l'énonciation, Histoire, Épistémologie, Langage, t. VIII, fascicule 2.

Traduction en portugais dans Historia e sentido na linguagem, Eduardo Guimarães (org.), Pontes Editores, 1989, Campinas.

d. (En collaboration avec Jacques Guilhaumou) «L'apport de l'analyse du discours à la saisie historique de l'événement: la journée révolutionnaire parisienne du 4 septembre 1793 », communication au colloque du Centre méridional d'histoire sociale d'Aix-enProvence (1983), dans L'événement, publication Lafitte-Université de Provence, p. 171 181.

\section{8}

(En collaboration avec Jacques Guilhaumou) «La langue française à l'ordre du jour (1789-1794) », Mots, 16, «Les langages de la Révolution française », dir. J. Guilhaumou, mars, p. 131-154. Traduit en allemand dans Lilli, 72, Göttingen, 1988, p. 60-79.

\section{9}

(En collaboration avec Jacques Guilhaumou et Régine Robin) «Jalons dans l'histoire de l'analyse de discours en France : un trajet des historiens du discours», Discours Social/Social Discourse, Cahiers de recherche en littérature comparée, vol. 2, nº 3, Université McGill, Montréal, p. 3-16.

\section{0}

34 a. "Éléments pour une histoire de l'analyse de discours en France », communication aux Rencontres «Linguistique et matérialisme » de Rouen (17,18 octobre 1988), publication dans Cahiers de linguistique sociale, 17, p. 63-76.

b. (En collaboration avec Jacques Guilhaumou) « De nouveaux gestes de lecture ou le point de vue de l'analyse de discours sur le sens ", dans La Quadrature du sens, recueil collectif publié par Claudine Normand, PUF.

c. (En collaboration avec F. Gadet, P. Henry, J. Léon et M. Plon) «Introduction» à la traduction anglaise d'Analyse automatique du discours (1969) de Michel Pêcheux, à paraître dans Konteksten, Amsterdam. Paru en portugais, Editora da Unicamp, Brésil.

37 d. Michel Pêcheux, l'inquiétude du discours. Choix et présentation de textes de Michel Pêcheux, Éditions des Cendres.

\section{1}

Entretien avec Henri Deluy, Les Lettres françaises, 8, avril, p. 17. 


\section{2}

39 a. «L'inquiétude du discours. Un trajet dans l'histoire de l'analyse du discours : le travail de Michel Pêcheux", communication au colloque d'ouverture du Centre interuniversitaire d'analyse du discours et de sociocritique des textes (CIADEST), 21-22 mars 1991, publié dans Discours social / Social Discourse, vol. 4. n 1-2 Montréal.

b. Article « Michel Pêcheux », Lexicon Grammaticorum, Niemeyer, Allemagne.

\section{4}

41 a. (En collaboration avec Jacques Guilhaumou et par les soins de Françoise Gadet et de Francine Mazière), «La mémoire et l'événement: le 14 juillet 1989 », Langages, 114 Histoire, mémoire, langage (Courtine éd.).

b. (En collaboration avec Jacques Guilhaumou et Régine Robin) Discours et archive. Expérimentations en analyse du discours. P. Mardaga, Liège. 